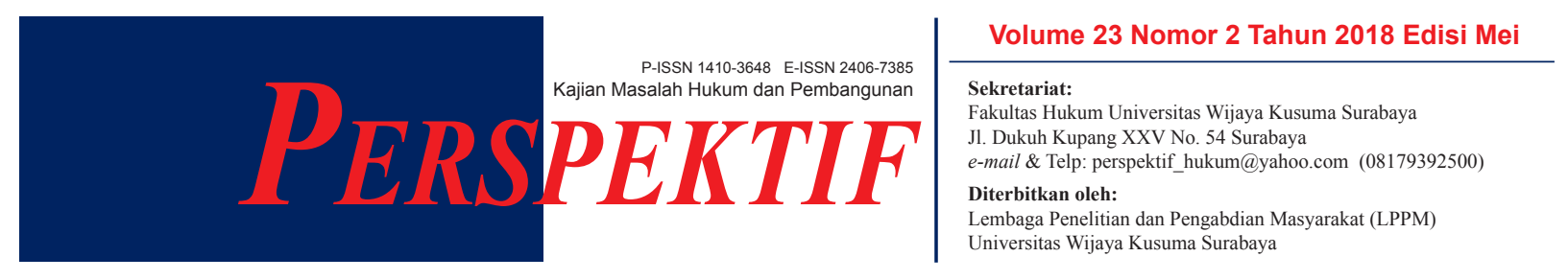

\title{
PERJANJIAN PERBATASAN LAUT ANTARA AUSTRALIA DENGAN TIMOR LESTE TERHADAP STATUS WILAYAH LAUT TIMOR
}

\author{
Irhas Novianti Yasma'un \\ Fakultas Ilmu Sosial dan Hukum, Universitas Negeri Surabaya \\ e-mail:irhasnovianti@gmail.com \\ Audi Fatchur Rahman \\ Fakultas Ilmu Sosial dan Hukum, Universitas Negeri Surabaya \\ e-mail: kedindinglorwijayakusuma@gmail.com \\ Nur Retno Ika Martiyah \\ Fakultas Ilmu Sosial dan Hukum, Universitas Negeri Surabaya \\ e-mail: nurretnoikamartiyah@gmail.com
}

\begin{abstract}
ABSTRAK
Negara Indonesia selaku negara pantai diwajibkan meletakkan batas teritorial laut yang sesuai dengan UNCLOS 1982 demi menjamin kepastian wilayah laut, darat, dan udara. Australia dan Indonesia mengadakan perjanjian mengenai batas wilayah laut. Pada tahun 2002 Timor Leste merdeka menjadi negara baru. Timor Leste tak punya batas laut permanen sementara Indonesia dan Australia berbagi kekayaan alam di Celah Timor. Pada tahun 2004 Timor Leste memulai kembali negoisasi dengan Australia. Pemerintah Indonesia menyatakan belum bisa mengambil sikap atas kesepakatan perbatasan maritim antara Timor Leste dengan Australia. Australia dan Timor Leste merupakan dua negara yang secara geografis berdekatan dengan Indonesia. Untuk itu, perlu adanya regulasi yang jelas agar status wilayah laut masing-masing negara dapat dipertanggungjawabkan. Kesepakatan perbatasan maritim antara Australia dan Timor Leste akan berimplikasi bagi wilayah laut Indonesia. Implikasi kesepakatan itu dapat memicu sengketa baru antara Indonesia dan Australia. Untuk mengetahui dampak perjanjian tersebut diperlukan analisa sesuai UNCLOS 1982 dan Hukum Internasional. Penelitian ini merupakan penelitian normatif. Kata Kunci: UNCLOS 1982; Perjanjian; Teritorial
\end{abstract}

\begin{abstract}
Indonesia as a coastal state is obliged to place a territorial sea boundary in accordance with UNCLOS 1982 in order to guarantee the certainty of sea, land and air. Australia and Indonesia have agreements on maritime boundaries. In 2002 East Timor became an independent state. Timor Leste has no permanent sea boundary while Indonesia and Australia share natural resources in the Timor Gap. In 2004 Timor Leste restarted negotiations with Australia. The Indonesian government says it has not been able to take a stand on the maritime boundary agreement between Timor Leste and Australia. Australia and Timor Leste are two countries geographically adjacent to Indonesia. Therefore, there needs to be a clear regulation so that the status of marine areas of each country can be accounted for. The maritime border agreement between Australia and Timor Leste will have implications for Indonesia's marine territory. The implications of the agreement could trigger a new dispute between Indonesia and Australia. To find out the impact of the agreement requires analysis according to UNCLOS 1982 and international. This is a normative research.
\end{abstract}

Keywords: UNCLOS 1982; Agreements; Territory 


\section{PENDAHULUAN}

Indonesia dan Australia menyepakati batas laut pada tahun 1989 yaitu Timor Gap Treaty. Timor Gap Treaty masih dalam bagian Timor Timur sebelum berubah menjadi Timor Leste. Tahun 2002, Timor Timur telah merdeka menjadi negara yang bernama Timor Leste. Pada tahun yang sama, Timor Sea Treaty ditandatangani namun tidak disepakati adanya batas maritim. Timor Leste berupaya mempertahankan ladang minyak yang berada pada wilayah laut teritorialnya sampai pada tahun 2004 Timor Leste kembali bernegoisasi dengan Australia. Pada tahun 2006 Australia dan Timor Leste menyepakati pembagian minyak dan gas dari Greater Sunrise.

Indonesia yang pernah menjadi bagian dari Timor Leste tidak dilibatkan dalam perjanjian yang dilakukan oleh Australia dan Timor Leste. Salah satu fakta hukum yang bisa dipakai Indonesia dalam pembicaraan batas perairan laut dengan Australia adalah Konvensi PBB tentang Hukum Laut Tahun 1982. Konvensi ini menetapkan bahwa jika pantai dua negara yang berbatasan langsung atau berdekatan satu sama lain, kedua negara tidak berhak untuk memperluas perairan laut teritorialnya melampaui garis pertengahan.

Pengaturan tentang batas-batas maritim antar negara telah diatur dalam pasal-pasal UNCLOS 1982. Dalam UNCLOS 1982 disebutkan beberapa wilayah perairan yang dimiliki oleh suatu setiap negara pantai, termasuk Indonesia. Wilayah perairan tersebut meliputi perairan pedalaman, laut teritorial, zona tambahan, Zona Ekonomi Eksklusif (ZEE), Landas Kontinen (LK), dan laut lepas. Hal ini dilakukan agar eksploitasi dan eksplorasi sumber daya alam yang ada di dalam wilayah laut dapat berjalan dengan baik tanpa adanya gesekan dengan negara manapun, khususnya negara tetangga. Suatu negara kepulauan yang memiliki batas wilayah laut yang pasti dapat menghindari konflik dan dapat mempertanggungjawabkan apabila ada permasalahan hukum. Sampai saat ini, perbatasan wilayah laut timor yang melibatkan Australia dan Timor Leste tetap pada tahap diplomasi. Upaya-upaya telah dilakukan agar keputusan yang disepakati dapat menguntungkan semua pihak.

Dalam penjelasan di atas, dapat diketahui bahwa Indonesia akan terkena dampak dari perjanjian tersebut. Belum ada kesepakatan yang permanen tentang batas perairan laut antara Indonesia dan Australia. Indonesia harus segera menyelesaikan perjanjian sebelum terjadi sengketa yang lebih serius melibatkan milyaran dolar cadangan minyak hilang sia-sia.

\section{METODE PENELITIAN}

Metode penelitian yang digunakan dalam penulisan ini menggunakan metode penelitian hukum normatif. Pada penelitan ini penulis terpusat pada penelitan taraf sinkronisasi hukum untuk mencari jawaban dari rumusan masalah yang telah dipertanyakan di atas. ${ }^{1}$ Sifat penelitian yang dilakukan bersifat deskriptif, yaitu memberikan gambaran tentang bagaimana dampak perjanjian Australia dan Timor Leste terhadap kedaulatan Laut Timor. Penelitian dilakukan dengan mengkaji data sekunder berupa UNCLOS 1982, Perjanjian Australia dan Timor Leste, dan konsep Hukum Laut Internasional.

\section{PEMBAHASAN}

Penentuan wilayah laut Indonesia seperti garis batas laut wilayah, batas ZEE, dan batas LK antara Indonesia dengan negara tetangga didasarkan pada Hukum Internasional salah satunya adalah UNCLOS 1982. Selain berpegang pada UNCLOS 1982, delimitasi garis batas Indonesia dengan negara tetangga juga berpegang pada prinsip-prinsip penarikan garis batas maritim yang berkembang di dalam Hukum Internasional, seperti di dalam berbagai yurisprudensi Mahkamah Internasional dan praktek negara-negara, ditambah dengan prinsip teknis penarikan batas yang telah disepakati oleh negara yang berbatasan. Selain Hukum Internasional seperti UNCLOS 1982, praktek negara-negara dan yurisprudensi Mahkamah Internasional, beberapa hukum nasional yang menjadi dasar delimitasi batas maritim dengan negara tetangga antara lain adalah Undang-Undang Nomor 17 Tahun 1985 tentang Konvensi Perserikatan Bangsa-Bangsa tentang Hukum Laut, Undang-Undang Nomor 43 Tahun 2008 tentang Wilayah Negara, Undang-Undang Nomor 5 Tahun 1983 tentang Zona Ekonomi

${ }^{1}$ Burhan Ashshofa. (2010). Metode Penelitian Hukum. Jakarta: Rineka Cipta, h. 14. 
Mirhas Novianti Yasma'un, Audi Fatchur Rahman, dan Nur Ika Martiyah

Ekslusif, Undang-Undang Nomor 1 Tahun 1973 tentang Landas Kontinen Indonesia. ${ }^{2}$

Perjanjian garis batas laut antara Australia dan Timor Leste yang telah disepakati pada Maret 2018 di markas besar PBB New York, Amerika Serikat tersebut merupakan sebuah momen bersejarah yang mengakhiri sengketa panjang antara Australia dan Timor Leste mengenai garis batas laut di wilayah selatan Timor Leste dengan Australia tersebut. Sejak awal kemerdekaan Timor Leste menuntut Australia untuk duduk bersama menegosiasikan batas laut mereka agar terciptanya batas laut yang jelas dan riil. Disamping itu pembagian batas laut tersebut terdapat juga pembagian wilayah eksplorasi dan eksploitasi blok migas yang dikenal dengan greater sunrise unit area. Dimana tentu dengan pembagian wilayah migas tersebut menambah pundi-pundi pendapatan Timor Leste dari sektor migas yang akhir-akhir ini mengalamai pelemahan.

Perjanjian ini di samping mengakhiri konflik Australia-Timor Leste, menimbulkan suatu potensi konflik yang terjadi antara Indonesia dengan Australia dimana penetapan garis batas wilayah laut AustraliaTimor Leste tersebut bersinggungan dengan garis batas wilayah laut Indonesia-Australia yang telah ditetapkan sejak tahun 1972. Indonesia sendiri telah melakukan perjanjian mengenai penetapan garis batas laut dengan Australia pada tahun 1972 yang membentang sepanjang daerah selatan Indonesia dengan Australia. Kesepakatan perbatasan wilayah laut antara Indonesia dan Australia pun harus menempuh proses yang berliku-liku, dikarenakan sejak awal pembentukan kesepakatan kedua negara memiliki perbedaan konsep dan pemahaman mengenai garis batas minimal dan maksimal landas kontinen yang saling tumpang tindih. Di mana Indonesia mendasarkan posisinya pada prinsip garis tengah (median line) yang kemudian diperkuat oleh Hukum Laut Internasional (UNCLOS 1982) sedangkan Australia berpegang teguh terhadap pengaturan landas kontinen berdasarkan Konvensi Jenewa Tahun 1958 yang menegaskan bahwa batas ditetapkan pada "bathtmetric axis" poros palung timor.

2 Tri Patmasari, Eko Artanto dan Astrit Rimayanti. Perkembangan Terakhir Batas Maritim Indonesia dengan Negara Tetangga. Jakarta: Pusat Pemetaan Batas Wilayah Badan Informasi Geospasial.
Perundingan ini banyak menemui jalan buntu yang akhirnya setelah berkali-kali perundingan ditemukan sebuah solusi yang sebenarnya tidak solutif. Dalam perundingan ke-7, tahun 1985, Australia bersepakat untuk membentuk Joint Development Zone, namun luas dan bentuknya merupakan sebuah masalah. Sikap Australia tetap mempertahankan pendirian bahwa "daerah sengketa" terletak di daerah antara poros palung timur dan garis median (median line), sedangkan daerah yang terletak antara median line dan garis 200 mil dari Pantai Timor Timur merupakan daerah yurisdiksi ekslusif Australia dan tidak dapat dijadikan daerah pengembangan bersama (joint development zone) kesepakatan selanjutnya terjadi tahun 1997 yang dilandasi pada prinsip garis tengah untuk menetapkan ZEE Indonesia sehingga hak penangkapan ikan di Indonesia sekarang semakin jauh ke selatan daripada hak atas dasar laut (minyak dan gas). Meskipun secara konkrit perjanjian tersebut tidak diratifikasi "menghormati" perjanjian tersebut.

Keadaan berubah ketika pada tahun 2002 Timor Leste mendapatkan kemerdekaan dengan sokongan luar biasa dari PBB. Timor Leste pun memulai perundingannya dengan Australia terkait garis batas laut wilayah selatannya yang berbatasan dengan Australia. Perundingan selama 16 tahun berakhir pada 7 Maret 2018. Kesepakatan ini berimplikasi terhadap keberlangsungan garis batas laut AustraliaIndonesia serta perjanjian-perjanjian lainnya yang berkaitan dengan garis batas wilayah laut kedua negara yang pernah disepakati sebelumnya. Pasca awal kemerdekaan Timor Leste pada 2002 Menteri Luar Negeri Australia saat itu, Alexander Downer, memperingatkan bahwa menggambar ulang batasbatas maritim dengan Timor Leste akan berisiko "mengurai" ribuan kilometer batas yang telah lama ada antara Australia dan Indonesia. Direktur Jenderal Bidang Hukum dan Perjanjian Internasional di Kementerian Luar Negeri Indonesia, Damos Agusman, mengatakan kepada Fairfax Media bahwa pemerintah Indonesia menginginkan perundingan baru mengenai Perjanjian Perth, yang ditandatangani pada tahun 1997.

Perjanjian tahun 1997 tersebut belum pernah berlaku karena Indonesia belum pernah meratifikasinya, walaupun kedua negara tersebut telah mematuhinya. Dokumen tersebut menetapkan 
ZEE antara Australia dan Indonesia dengan menggunakan garis tengah antara kedua negara komplektifitas perundingan tentu akan semakin intens apabila Indonesia menginginkan negosiasi ulang mengenai pengaturan garis batas wilayah lautnya dengan Australia bahkan Timor Leste pasca perjanjian Australia-Timor Leste Maret lalu.

Kerumitan ini terjadi karena perundingan harus melibatkan 3 (tiga) negara di mana ada skenarioskenario terburuk yang menyebabkan adanya perubahan-perubahan masif antara garis batas Indonesia-Australia yang telah lama ditetapkan atau bahkan tidak menutup kemungkinan adanya negosiasi atau perundingan ulang antara Australia-Timor Leste bahkan Indonesia-Timor Leste. Disamping itu keberatan Australia atas perundingan ulang yang mungkin saja Indonesia lakukan adalah adanya potensi kerugian atau berkurangnya pendapatan di wilayah eksplorasi migas greater sunshine area apabila Indonesia masuk ke dalamnya sebagai akibat dari re-negotiation antara Indonesia-Australia.

Area eksplorasi dan eksploitasi sumber daya alam berupa migas yang bernilai milyaran US Dollar tersebut merupakan wilayah yang telah lama dipersengketakan antara Timor Leste dan Australia sehingga pada perjanjian Australia-Timor Leste mengenai garis batas laut kedua negara yang baru saja ditandatangai oleh kedua negara di markas besar PBB di New York, Amerika Serikat membawa angin segar bagi Timor Leste karena Timor Leste digadang-gadang mendapatkan sekitar $\$ 64,5$ (enam puluh empat koma lima) miliar dollar dalam bentuk pendapatan.

\section{PENUTUP}

\section{Kesimpulan}

Perjanjian Australia-Timor Leste bisa dikatakan menjadi kesempatan emas bagi Indonesia untuk memberanikan diri mengajukan negosiasi ulang dengan Australia bahkan kalau perlu dengan Timor Leste karena terdapat garis batas wilayah laut Australia-Timor Leste yang bersinggungan dengan garis batas wilayah laut Indonesia-Australia. Adanya negosiasi atau perundingan ulang ini oleh beberapa pakar dianggap memberatkan Australia karena beberapa faktor, diantaranya adalah: pertama, harus merombak ulang garis batas wilayah laut IndonesiaAustralia dengan panjang ribuan mil; kedua, adanya skenario terburuk mengenai perundingan 3 (tiga) pihak yaitu Indonesia, Timor Leste, dan Australia yang tentunya memakan waktu dan biaya serta proses diplomasi yang rumit karena penuh dengan konflik kepentingan; ketiga, ada kemungkinan bahwa dengan diselenggarakannya negosiasi ulang maka Indonesia akan mendapatkan hak secara hukum atas wilayah atau blok eksplorasi dan eksploitasi migas yang disebut greater sunshine area dengan potensi pendapatan puluhan milyar dollar amerika, keempat adanya potensi Australia akan mengalamai kerugian atau berkurangnya keuntungan dengan adanya negosiasi ulang garis batas wilayah laut Australia-Indonesia. Implikasi paling konkrit dengan adanya perjanjian Australia-Timor Leste tentu adanya kepastian wilayah dan hukum yang didapat oleh Australia dan Timor Leste karena perselisihan panjang yang terjadi antara kedua negara tersebut mengenai pembagian batas wilayah laut berakhir. Disamping itu ada implikasi nyata dan krusial yang harus dihadapi oleh Indonesia-Australia, adanya persinggungan yang terjadi antara garis batas wilayah laut Australia-Timor Leste dengan AustraliaIndonesia menjadi sebuah problematika kompleks yang harus segera dirundingkan dikarenakan dapat berpengaruh terhadap hubungan jangka panjang kedua negara bahkan tiga negara dengan Timor Leste.

\section{Rekomendasi}

Saran kami setelah melakukan analisis dengan berbagai sumber yang didapat secara daring maupun luring terlebih melalui media asing yang mengulas kasus ini secara rinci dan mendetail, adalah Indonesia harus dengan segera melakukan negosiasi atau perundingan ulang dengan Australia atau sebaliknya. Adanya persinggungan garis batas wilayah laut tersebut menyebabkan rawan konflik dan menyebabkan keruhnya hubungan diplomatik bilateral Indonesia-Australia atau bahkan multilateral yaitu dengan Indonesia-Timor Leste-Australia. Dengan adanya potensi konflik yang masif dan intens akibat permasalahan yang cukup sensitif yaitu mengenai batas negara dan batas wilayah laut yang berimplikasi terhadap adanya ancaman keamanan serta kedaulatan suatu negara menempatkan kasus ini harus menjadi top priority untuk segera dirundingkan agar tidak terjadi kesalahpahaman, serta adanya tindakan-tindakan gegabah yang tidak diperlukan. 
Mirhas Novianti Yasma'un, Audi Fatchur Rahman, dan Nur Ika Martiyah

Semua tindakan diatas sifatnya preventif, tentunya tidak ada satupun negara yang menginginkan adanya suatu ketegangan yang menciptakan kepanikan sehingga kondisi suatu negara menjadi tidak stabil.

\section{DAFTAR PUSTAKA}

\section{Peraturan Perundang-undangan:}

Undang-Undang Nomor 1 Tahun 1973 tentang LKI. Undang-Undang Nomor 5 Tahun 1983 tentang ZEE. Undang-Undang Nomor 17 Tahun 1985 tentang Konvensi Perserikatan Bangsa-Bangsa tentang Hukum Laut.

Undang-Undang Nomor 43 Tahun 2008 tentang Wilayah Negara.

\section{UNCLOS 1982.}

\section{Buku:}

Burhan Ashshofa. (2010). Metode Penelitian Hukum. Jakarta: Rineka Cipta.

\section{Website:}

Anne Barker(ABC NEWS). "Perjanjian Batas Laut Australia-Timor Leste Bisa Pengaruhi Indonesia”. 6 Maret 2018. diakses dari https:// www.matamatapolitik.com/australia-dan-timorleste-sepakati-perjanjian-maritim-perbatasandengan-indonesia-terancam/, tanggal 20 April 2018 Pukul 19:18 WIB.

"Perjanjian Batas Laut Australia-Timor Leste Bisa Pengaruhi Indonesia". 6 Maret 2018. diakses dari http://www.abc.net.au/ indonesian/2018-03-06/perjanjian-maritimaustralia-timor-leste-bisa-pengaruhiindones/9517468. tanggal 20 April 2018 Pukul 19:18 WIB.

http://e-journal.uajy.ac.id/8033/2/1MIH01196.pdf

http://internasional.republika.co.id/berita/ internasional/abc-australia-network/18/03/06/ p55h0q366-perjanjian-batas-laut-aussietimorleste-bisa-pengaruhi-ri

http://jhp.ui.ac.id/index.php/home/article/ viewFile/375/310

http://www.abc.net.au/indonesian/2018-03-06/ perjanjian-maritim-australia-timor-leste-bisapengaruhi-indones/9517468.

http://www.australiaplus.com/indonesian/berita/ perjanjian-maritim-australia-timor-leste-bisapengaruhi-indones/9518252

https://www.matamatapolitik.com/australia-dantimor-leste-sepakati-perjanjian-maritimperbatasan-dengan-indonesia-terancam/

https://www.matamatapolitik.com/indonesia-incarperjanjian-maritim-setelah-kesepakatan-timorleste-australial

https://www.smh.com.au/world/asia/indonesia-eyeschange-to-maritime-treaty-after-timor-australiadeal-20180307-p4z39v.html

James Massola (Sydney Morning Herald). "Indonesia Eyes Change to Maritime Treaty after TimorAustralia Deal". 7 Maret 2018. diakses dari https://www.smh.com.au/world/asia/indonesiaeyes-change-to-maritime-treaty-after-timoraustralia-deal-20180307-p4z39v.html. tanggal 20 April 2018 Pukul 19:49 WIB.

Mochtar Kusumaatmadja. "Perjanjian IndonesiaAustralia di Celah Timor". Juni 1992. diakses dari http://jhp.ui.ac.id/index.php/home/article/ viewFile/375/310. tanggal 20 April 2018 Pukul 19:13 WIB.

Syaiful W. Harahap. "Australia-Timor Leste Sepakati Batas Laut Garis Pertengahan, Bagaimana dengan Indonesia?". Kompasiana. 7 Maret 2018. https://www.kompasiana. com/infokespro/5a9f5f9ccf01b459e901c002/ australia-timor-leste-sepakat-batas-laut-garispertengahan-bagaimana-dengan-indonesia . Diakses 19 April 2018 Pukul 22:49 WIB. 